\title{
Clinical Features of Food Allergy during the 1st Year of Life: The ADAPAR Birth Cohort Study
}

\author{
Dilek Doğruel Gülbin Bingöl Derya Ufuk Altıntaş Mustafa Yılmaz \\ Seval Güneşer Kendirli \\ Department of Pediatric Allergy and Immunology, Balcalı Hospital, Faculty of Medicine, Çukurova University, \\ Adana, Turkey
}

\section{Key Words}

Birth cohort study · Cord blood · Food allergy · Oral food challenge

\begin{abstract}
Background: Although food allergies (FAs) occur most commonly during the 1 st year of life, there is limited information available regarding the epidemiology of FAs. In this study, we investigated the incidence of FA and the associated risk factors during the 1 st year of life in southeast Turkey. Methods: This study is a prospective evaluation of 1,377 infants born at the Balcalı Hospital (Çukurova University) and includes four routine follow-up assessments until the age of 1 year. At birth, a physical examination was performed, cord blood samples were taken, and parents completed a baseline questionnaire. Follow-up visits were scheduled at 3, 6 and 12 months and included the infants' physical examination and a follow-up questionnaire. A skin prick test (SPT) was performed and food-specific lgE levels were measured at 6 and 12 months. Telephone interviews were conducted when the infants were 9 months of age, and the questionnaire was administered. The diagnosis of FA was based on food-specific lgE levels, positive SPT results, associated clinical findings and an oral food challenge (OFC) test. Results:
\end{abstract}

Patient histories, physical examinations and laboratory results indicated a possible FA in 90 infants (6.5\%) during the 1 st year of life. All of them underwent OFC testing with the suspected foods, and FA was confirmed in 33 cases (2.4\%). Cow's milk allergy was the major cause of FA. Skin reactions were major clinical findings in FA. A family history of atopy was identified as the major risk factor for FA. Conclusions: The prevalence and risk factors of FA in our region are consistent with those reported in the literature.

두 2016 S. Karger AG, Base

\section{Introduction}

Food allergy (FA) can occur at any age, although the age group from 0 to 3 years is most commonly affected. Overperception of FA in the community, absence of a screening test, failure to diagnose the condition with a single test, and the cumbersome and time-consuming nature of provocation tests contribute to the difficulty in conducting population-based trials [1]. Similar to other parts of the world, a limited number of studies has been conducted on the epidemiology of allergic diseases in Turkey. It has been reported that the frequency of FA among infants up to 3 years of age is $6-8 \%$ in western

\section{KARGER}

E-Mail karger@karger.com

www.karger.com/iaa (c) 2016 S. Karger AG, Basel

$1018-2438 / 16 / 1693-0171 \$ 39.50 / 0$
Correspondence to: Dr. Gülbin Bingöl

Department of Pediatric Allergy and Immunology, Balcalı Hospital

Faculty of Medicine, Çukurova University

TR-01330 Balcalı, Adana (Turkey)

E-Mail bingolgulbin@gmail.com 
countries [2]. In the first birth cohort study by Altıntaş et al. [3] in our region, the incidence of cow's milk allergy was found to be $1.55 \%$.

Cohort studies are of fundamental importance and value in defining the mechanism responsible for the development of allergic diseases [4]. Particularly birth cohort studies help to elucidate the development of the disease through a longitudinal approach. Although there are no general recommendations for the prevention of FA, some previous studies have defined several risk factors for FA development. These factors include a family history of atopic disease [5], environmental exposure to allergens (including microbes, cigarette smoke and other pollutants) [6], age at solid food introduction and duration of breastfeeding $[7,8]$. A determination of these risk factors might lead to recommendations for the prevention of FA.

Several studies have been performed to shed light on possible associations between elevated immunoglobulin (Ig)E levels in the cord blood and the development of allergic diseases in later stages of life. To date, contradictory results have been reported for the association between a high cord blood IgE level and atopy. Small sample sizes and brief observation periods used in most of the studies and failure to use objective findings for allergen sensitization in some studies may have contributed to these contradictory results [9-11].

The ADAPAR (Adana Pediatric Allergy and Risk Factor) birth cohort study aimed to establish the incidence of FA and associated risk factors in infants followed up from birth until 1 year of age in Adana, a large city in Southeast Turkey on the Mediterranean Sea.

\section{Materials and Methods}

\section{Study Design}

The ADAPAR birth cohort study was a population-based study conducted in a single center on unselected subjects. It included 1,475 infants delivered at the Balcalı Hospital (Çukurova University) in Adana between February 2010 and February 2011. The local Human Research Ethics Committee approved the study. All parents gave written informed consent for the participation in the study.

A number of tests and examinations were carried out at the time of delivery and at follow-ups (fig. 1). A physician performed the clinical examination and cord blood sampling of each infant at birth. The study questionnaires about the infants were of two types: the baseline questionnaire was completed by the mother at birth and follow-up questionnaires were completed at multiple time points. The former questioned about the medical characteristics of the pregnancy (i.e. accompanying chronic disorders, nutritional supplements, drugs and smoking status), familial predisposition to allergic disorders (e.g. asthma, allergic rhinitis, FA and atopic dermatitis, $\mathrm{AD}$ ), exposure to domestic allergens (e.g. smoking, pets and molds) and the demographic characteristics of the family. Patient records were used to obtain information about each infant at birth, including gender, weight and gestational age at birth, for example.

The patients were appointed to control visits 3, 6 and 12 months after conception. While the same physician who performed the first examination examined the infants, the mother of each infant filled in the follow-up questionnaire form. This way, information regarding breastfeeding and infant diet was obtained, and questions about nutritional supplements, infectious diseases, medications, vaccinations, smoking in the household, and signs and symptoms of allergic disorders were asked. At the 9-month followup, mothers were called via telephone and asked to complete an extended follow-up questionnaire a second time. Physical examination, skin prick tests (SPT) and specific (s)IgE level measurement were carried out when there was any suspicion of an allergic disease at that time. Additionally, SPTs were performed and sIgE was measured at 6 and 12 months of age. When follow-up examinations were missed and infants could not be examined, the mothers were contacted via phone and the same extended questionnaire was completed by them.

The 12th-month interview was completed in 1,377 (93.3\%) infants, who were enrolled in the study. In addition, SPT and SIgE level measurements were carried out when there was any suspicion of allergic disease raised by history and/or physical examination.

\section{Cord Blood Collection and Analysis}

In all participants, the umbilical cord was sterilized and cord blood at an amount of $5 \mathrm{ml}$ was drawn from the umbilical vein immediately after delivery. The samples were then centrifuged at $3,000 \mathrm{rpm}$ for $15 \mathrm{~min}$, and their sera were preserved at $-30^{\circ} \mathrm{C}$ until further biochemical analyses. The ImmunoCAP ${ }^{\circledR}$ specific IgE test (UniCAP; Phadia, Uppsala, Sweden) was used to measure cord blood IgE levels (expressed in kUA/l). To prevent the influence of contamination with maternal blood, in addition to IgE testing, all cord samples were also tested for IgA at the Biochemistry Laboratory of the Çukurova University on the same day. The quantifications of IgA levels were measured by the turbidimetric method (Beckman Coulter Unicel DXC 800). IgA results $\geq 11 \mathrm{mg} / \mathrm{dl}$ led to the exclusion of the cord blood IgE result.

\section{Food-Specific IgE Measurements}

At the start of the study, a screening test was carried out using an ImmunoCAP ${ }^{\circledR}$ kit in infant sera for the six most common food allergens. A positive screening test prompted the analysis of $\operatorname{IgE}$ levels specific to cow's milk, hen's eggs, soy, wheat, fish and peanuts, and levels $>0.35 \mathrm{kU} / \mathrm{l}$ were considered positive.

\section{Skin Prick Tests}

Commercially available extracts of major inhalant allergens (Allergopharma, Germany) were used for SPTs: tree (alder, hazel, poplar, elm and sallow), mold (Alternaria alternata, Cladosporium herbarum and Fusarium moniliforme), pollen (grass, barley, oat, rye, wheat, velvet, orchard, timothy, blue grass and meadow fescue), Dermatophagoides pteronyssinus and D. farinae, and food allergens (milk, egg, wheat, peanut and banana). The SPTs included standard methods [12]; when the mean wheal size was more than $3 \mathrm{~mm}$ larger than the negative control, the result was deemed positive. 
Fig. 1. The scheduled follow-up assessments during the study. At the 3- and 9-month follow-ups, physical examination, SPT and specific IgE measurements were carried out when there was any suspicion of allergic disease.

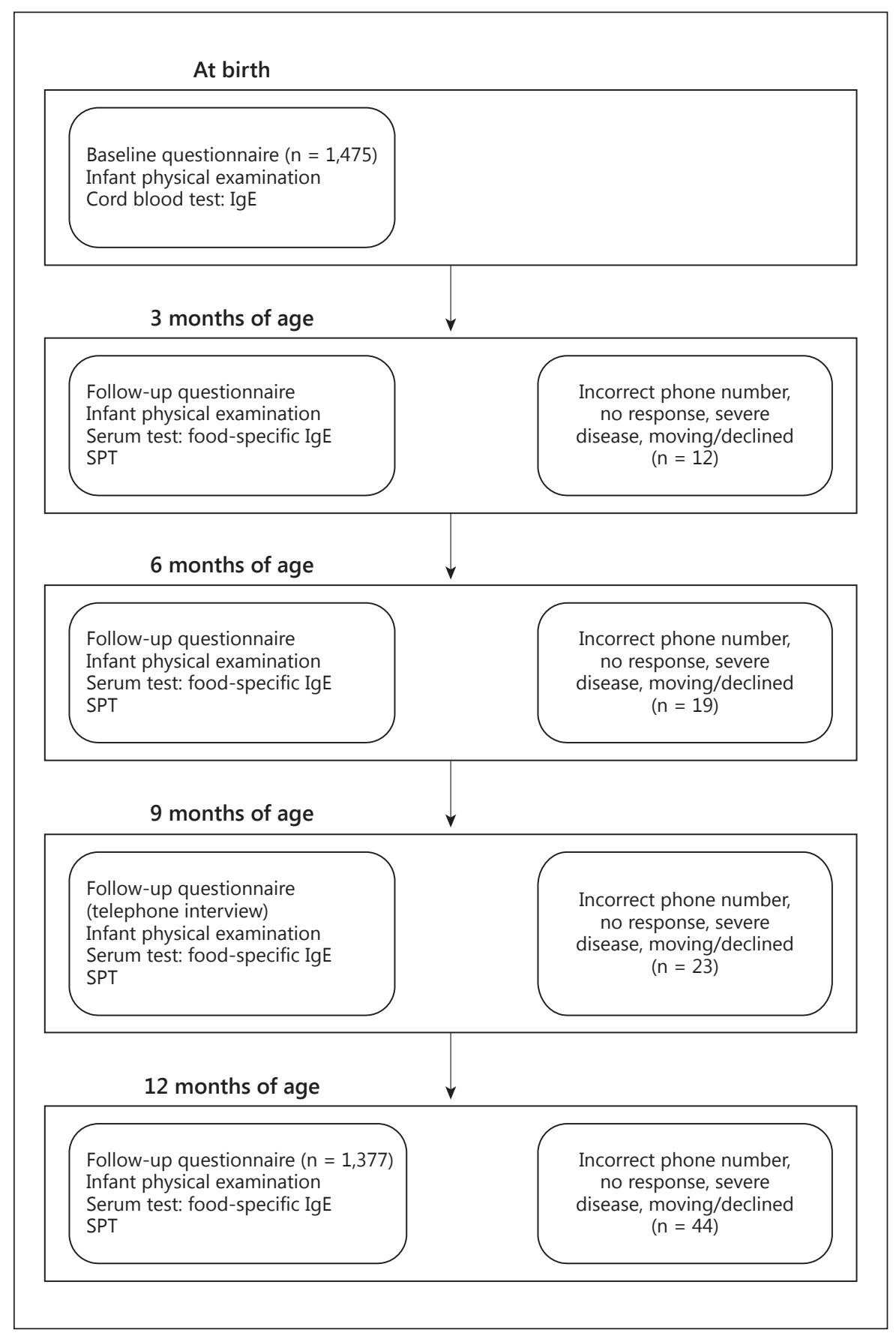

\section{Diagnostic Procedure}

FA was suspected in infants who had a history of any reaction related either to the skin or/and the respiratory/gastrointestinal system after intake of a specific food; infants with a serum sIgE $>0.35 \mathrm{kUA} / \mathrm{l}$, or infants with a positive SPT. These infants underwent elimination diet and were then offered an oral food challenge (OFC) [13]. Prior to testing, infants followed an elimination diet for 15 days. All suspected foods were eliminated from the infant's diet or the mother's diet when the infant was breastfed.

A Birth Cohort Study on Food Allergy
Standardized OFCs were performed in children with suspected FA [14]. The suspected food was administered starting at a minimum amount, and then incremental doses were given at 20 -min intervals until the total challenge dose was tolerated or an adverse reaction occurred. The starting dose of the food was determined according to the history of reaction intensity, or the results of $\operatorname{sgE}$ or SPT. The administered total dose was the normal daily intake of the food in question adjusted for age in months. The infants were observed for at least $2 \mathrm{~h}$ after the last dose before going home. The 
Table 1. Sensitization in infants with FA at the different follow-ups

\begin{tabular}{|c|c|c|c|c|c|c|c|c|c|c|c|c|c|c|c|}
\hline & \multicolumn{15}{|c|}{ Tests/examinations, $\mathrm{n}$} \\
\hline \multicolumn{16}{|l|}{ Positive tests } \\
\hline Egg & - & 5 & 5 & 14 & 31 & 34 & 4 & 13 & 14 & 2 & 13 & 14 & 20 & 62 & 67 \\
\hline Milk & 1 & 2 & 2 & 11 & 13 & 15 & 3 & 7 & 8 & 6 & 11 & 12 & 21 & 33 & 37 \\
\hline Wheat & 1 & 1 & 1 & - & 1 & 1 & - & - & - & 3 & 4 & 4 & 4 & 6 & 6 \\
\hline Chicken meat & - & - & - & - & - & - & 1 & 1 & 1 & 1 & - & 1 & 2 & 1 & 2 \\
\hline Beef & - & - & - & - & - & - & - & - & - & 1 & 2 & 2 & 1 & 2 & 2 \\
\hline
\end{tabular}

$\mathrm{SPT} / \mathrm{IgE}=\mathrm{SPT}$ and/or IgE. ${ }^{\mathrm{a}}$ Infants with at least one clinical examination. ${ }^{\mathrm{b}}$ Infants with at least one SPT/IgE tested. ${ }^{\mathrm{c}}$ One infant did not undergo OFC due to a history of anaphylaxis.

parents of all infants were contacted via telephone $72 \mathrm{~h}$ after test completion in order to determine any findings suggestive of FA. FAs were defined as positive when urticaria, angioedema, vomiting, diarrhea, flare-ups of eczema, or respiratory and cardiovascular symptoms developed during the challenge procedure.

\section{Statistical Analysis}

Data were analyzed using SPSS for Windows v. 15.0. Findings in the groups with and without FA were statistically compared. Relationships between FA in infancy and various maternal, environmental and perinatal risk factors were assessed using Pearson's $\chi^{2}$ test. The Mann-Whitney U test was used to compare the groups' cord blood IgE concentrations. Post hoc tests were used in all groups with significant statistical difference in ANOVA to identify the groups with a higher mean. Multiple logistic regression analysis was used to analyze the effects of factors that were identified as statistically significant or considered clinically important for FA. Results were presented as odds ratio with 95\% confidence intervals. A p value $<0.05$ was considered statistically significant for all tests.

\section{Results}

\section{Characteristics of the Participants}

Among 1,475 potential participants, 1,377 infants (93.3\%; 732 boys and 645 girls) were finally enrolled in the study. Moving of a family to another residence, severe disease or poor parental cooperation were the main causes of failure to participate. The majority (920 infants) under- went at least one SPT and/or food-specific IgE determination by the end of 1 year (table 1 ).

There were no significant differences with respect to race/ethnicity between participants and those who declined. The characteristics of the infants enrolled have been described elsewhere [15].

\section{Cord Blood IgE and IgA Levels}

Cumulative IgA levels for all cord blood samples were $<11 \mathrm{mg} / \mathrm{dl}$. The mean cord blood IgA value was $8.5 \pm 2.2$ $\mathrm{mg} / \mathrm{dl}$. No statistically significant relationship was observed regarding cord blood IgA and IgE levels ( $p>0.05$ ). The mean cord blood IgE level of the 1,377 infants was $28.9 \pm 19.2 \mathrm{kU} / \mathrm{l}$ (median: $25.0 \mathrm{kU} / \mathrm{l}$, range, 13-49 kU/l). We did not find any relationship between cord blood IgA level and FA outcome ( $\mathrm{p}>0.05)$.

\section{Clinical Characteristics and Laboratory Findings of FA Infants}

During the study, SPT was applied at least once and/ or sIgE was determined in 920 infants, and 115 tests were positive $(115 / 920=12.5 \%)$. Based on the positive $\operatorname{sIgE}$ and/or SPT, 115 foods were tested in total, and in 90 infants, reactions were considered suspicious $(90 / 920=$ $9.8 \%)$.

OFC was not performed in 1 infant because of a history of anaphylaxis following cow's milk consumption. In 


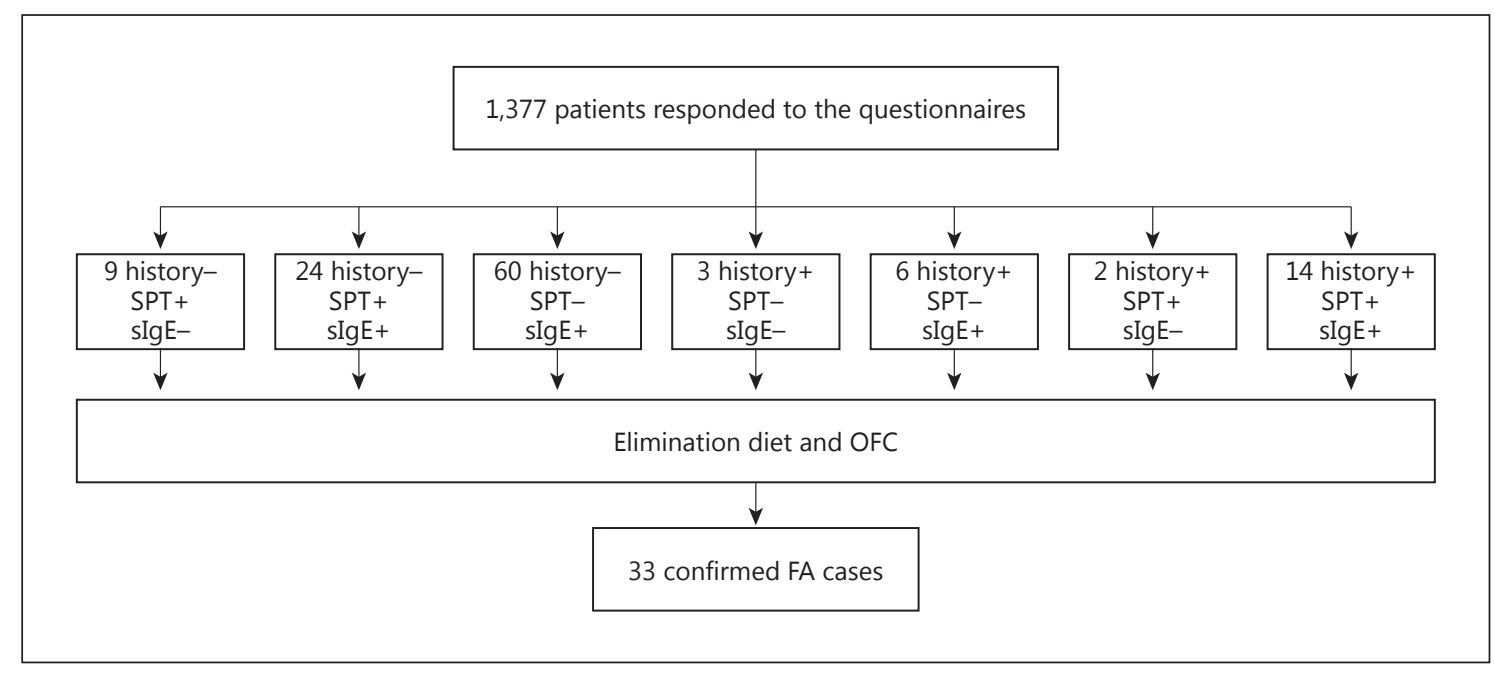

Fig. 2. Diagnostic procedure for FA. One infant did not undergo OFC due to a history of anaphylaxis.

total, 114 OFC tests were performed on 89 infants with positive SPTs and/or positive food-specific IgE. Among all OFCs, 38 tests $(38 / 114=33.3 \%)$ were found to be positive. A positive OFC was observed in $32(32 / 89=35.9 \%)$ infants (fig. 2).

In 11 of 13 infants with a positive history as well as a positive SPT and sIgE levels, the OFC test yielded a positive result (84.6\%). However, OFC was found to be positive in 4 of 8 infants with a positive clinical history and at least one positive laboratory test (sIgE and/or SPT). Interestingly, positive OFCs were found in 18 of 93 patients (19.3\%) whose parents were not aware of food-related symptoms despite the positive sIgE and/or SPT. OFC was also performed in 3 infants with a negative SPT and $\operatorname{sigE}$ levels because their families reported allergic symptoms; consequently, FA was diagnosed in 1 of them. In fact, this patient was regarded as having non-IgE FA (fig. 2). The frequencies of sensitization (SPT/sIgE) and OFC results at each follow-up are shown in table 1 .

FA was diagnosed in 33 of 1,377 infants (2.4\%). Of the infants diagnosed with FA, $66.6 \%$ were male $(n=22)$ and $33.4 \%(\mathrm{n}=11)$ were female. The age at diagnosis was 6.9 \pm 2.8 months. Frequencies of FA are presented for each follow-up visit in table 1.

Cutaneous symptoms (urticaria, maculopapular rash, angioedema and eczema) were the most common symptoms occurring during food challenge $(\mathrm{n}=28 ; 74 \%)$. As the second most common symptom, gastrointestinal symptoms (vomiting, nausea and food rejection) were observed in 7 patients (18\%); 3 patients showed respiratory
Table 2. Reactions observed during OFC

\begin{tabular}{lrrrllll}
\hline Food allergens & Milk & Egg & Wheat & $\begin{array}{l}\text { Chicken } \\
\text { meat }\end{array}$ & Banana & Total \\
\hline Cutaneous & 10 & 16 & - & 1 & 1 & $28(71.8 \%)$ \\
GI system & 6 & 1 & - & - & - & $7(18 \%)$ \\
Respir. system & 3 & - & - & - & - & $3(7.7 \%)$ \\
Systemic reaction & 1 & - & - & - & - & $1(2.5 \%)$ \\
\hline Total & 20 & 17 & - & 1 & 1 & $39(100 \%)$ \\
\hline
\end{tabular}

$\mathrm{GI}=$ Gastrointestinal. One infant did not undergo OFC due to a history of anaphylaxis.

symptoms (bronchospasm, nasal discharge and nasal stuffiness; table 2). Twenty-two reactions (57.9\%) developed during the first $2 \mathrm{~h}$ (early-onset reactions) while $42.1 \%(\mathrm{n}=16)$ occurred within $72 \mathrm{~h}$ (late-onset reactions). Early-onset reactions included cutaneous $(56.5 \%, \mathrm{n}=13)$, gastrointestinal $(30.4 \%, \mathrm{n}=7)$ and respiratory tract $(8.7 \%$, $\mathrm{n}=2$ ) reactions, whereas late reactions included cutaneous $(93.8 \%, \mathrm{n}=15)$ and respiratory tract $(6.2 \%, \mathrm{n}=1)$ reactions. While all of the early-onset skin reactions were in the form of pruritus and urticaria, all of the late-onset skin reactions were exacerbations of eczema.

Culprit allergens established by OFC test included cow's milk $(n=20,51.3 \%)$, eggs $(n=17,43.7 \%)$, chicken meat $(\mathrm{n}=1,2.5 \%)$ and bananas $(\mathrm{n}=1,2.5 \%$; table 2$)$. SPT, sIgE and OFC findings in patients diagnosed with FA are presented in table 3 . 
Table 3. Clinical and laboratory findings of the FA infants

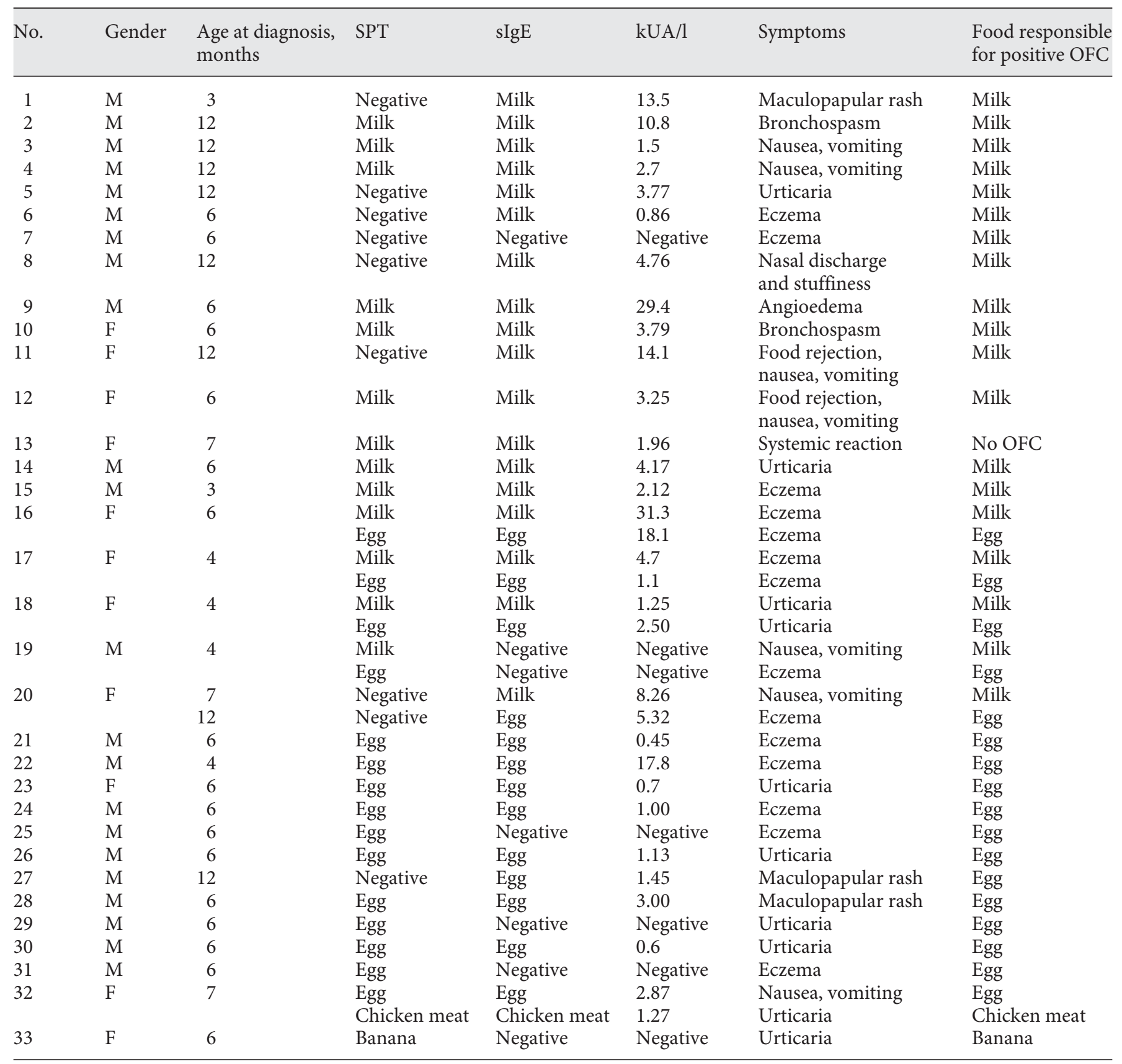

Risk Factors for the Development of FA

Table 4 summarizes comparisons of demographic and questionnaire findings for the groups with and without FA. Male gender was predominant among infants with FA compared to infants without FA $(p=0.027)$. Presence of $\mathrm{AD}$, a history of wheezing and a history of atopic disease in a family member (mother, father or sibling) were found to be significantly higher in the infants with than without FA ( $\mathrm{p}<0.05)$.

The mean cord blood IgE value was $39.17 \pm 26.3 \mathrm{kU} / \mathrm{l}$ in infants with FA and $28.56 \pm 1.54 \mathrm{kU} / \mathrm{l}$ in non-FA infants; there was no statistically significant association between elevated cord blood IgE level and the development of FA ( $p>0.148)$. 
The results regarding the effects of potential risk factors for FA are presented in table 5. Results of multiple regression analysis showed that the presence of FA in the other sibling (odds ratio 18.90, 95\% confidence interval 1.59-224.05) substantially increased the risk for FA development.

\section{Other Allergic Diseases}

At the end of the 1st year, eczema was diagnosed in 59 $(4.3 \%)$ infants. Of these infants, $12(20.3 \%)$ showed sensitivity against 14 different foods proven by OFC. At least one wheezing attack occurred in 220 infants during the 1 st year of life (16\%). FA was more common in wheezy infants (4\%) compared to the others (2\%), and the difference was statistically significant $(\mathrm{p}=0.036)$

During the study, no inhalant allergen sensitivity was detected with SPT among the infants.

\section{Discussion}

Allergic diseases cause significant morbidity during childhood. Globally, and particularly in developed countries, the frequency of allergic diseases among children is on the increase and FA prevalence differs from one country to another and even between different regions of the same country [16]. Differences in the lifestyle and environmental conditions in addition to the genetic background may play important roles in the development of allergic diseases [17]. In developed countries, preventive and protective measures against allergic diseases are being developed based on risk factors established in cohort studies, which were conducted particularly during infancy and childhood. However, very few birth cohort studies have been conducted in developing countries.

Although the true incidence of FA is difficult to establish due to the differences in methodology, among children FAs are reportedly on the rise [16]. This is the first publication of a cohort study on FA in the 1st year of life in Turkey. We found that the prevalence of FA is $2.4 \%$ in children younger than 12 months of age in Adana, Turkey. The prevalence of FA in the present study is consistent with other reports in the literature [17-19]. Some other birth cohort studies have reported higher FA prevalence rates [20-22]. However, the higher prevalence observed in those studies may have been caused by the lack of food challenge testing. The only birth cohort study ever conducted in our country by Altıntaş et al. [3] found a prevalence of $1.55 \%$ for cow's milk allergy in 1995 in
Table 4. Comparisons of demographic and questionnaire findings in the groups with and without FA

\begin{tabular}{|c|c|c|c|c|c|}
\hline & \multicolumn{2}{|c|}{$\begin{array}{l}\text { Infants } \\
\text { with FA }\end{array}$} & \multicolumn{2}{|c|}{$\begin{array}{l}\text { Infants } \\
\text { without FA }\end{array}$} & \multirow[t]{2}{*}{$\begin{array}{l}\mathrm{p} \\
\text { value }\end{array}$} \\
\hline & $\mathrm{n}$ & $\%$ & $\mathrm{n}$ & $\%$ & \\
\hline \multicolumn{6}{|l|}{ Gender } \\
\hline Male & 22 & 66.6 & 709 & 52.8 & \multirow[t]{2}{*}{0.027} \\
\hline Female & 11 & 33.4 & 635 & 47.2 & \\
\hline \multicolumn{6}{|l|}{ Gestational age } \\
\hline$<37$ weeks & 4 & 12.1 & 215 & 16 & \multirow[t]{2}{*}{0.274} \\
\hline$\geq 37$ weeks & 29 & 78.9 & 1,129 & 84 & \\
\hline \multicolumn{6}{|l|}{ Socioeconomic level } \\
\hline Low & 13 & 39.4 & 685 & 51 & \multirow[t]{3}{*}{0.067} \\
\hline Medium & 10 & 30.3 & 428 & 31.8 & \\
\hline High & 10 & 30.3 & 231 & 17.2 & \\
\hline \multicolumn{6}{|l|}{ Maternal education } \\
\hline Illiterate (1) & 1 & 3 & 120 & 8.9 & \multirow[t]{5}{*}{$0.001^{\mathrm{a}}$} \\
\hline Literate (2) & 2 & 6.1 & 14 & 1 & \\
\hline Primary school (3) & 14 & 42.4 & 893 & 66.4 & \\
\hline High school (4) & 5 & 15.2 & 107 & 8 & \\
\hline University (5) & 11 & 33.3 & 210 & 15.6 & \\
\hline \multicolumn{6}{|l|}{ Paternal education } \\
\hline Illiterate & 1 & 3 & 63 & 4.7 & \multirow[t]{5}{*}{0.080} \\
\hline Literate & 0 & 0 & 8 & 0.6 & \\
\hline Primary school & 15 & 45.5 & 857 & 63.8 & \\
\hline High school & 6 & 18.2 & 131 & 9.7 & \\
\hline University & 11 & 33.3 & 285 & 21.2 & \\
\hline \multicolumn{6}{|c|}{ Maternal history of allergic diseases } \\
\hline Yes & 12 & 36 & 137 & 10.2 & \multirow[t]{2}{*}{0.001} \\
\hline No & 21 & 64 & 1,207 & 89.8 & \\
\hline \multicolumn{6}{|c|}{ Paternal history of allergic diseases } \\
\hline Yes & 4 & 12.1 & 48 & 3.6 & \multirow[t]{2}{*}{0.006} \\
\hline No & 29 & 87.9 & 1,296 & 96.4 & \\
\hline \multicolumn{6}{|c|}{ History of allergic disease in a sibling } \\
\hline Yes & 7 & $21.2^{\circ}$ & 85 & 6.3 & \multirow[t]{2}{*}{0.001} \\
\hline No & 26 & 78.8 & 1,259 & 93.7 & \\
\hline \multicolumn{6}{|l|}{ History of wheezing } \\
\hline Yes & 9 & 27.2 & 211 & 15.8 & \multirow[t]{2}{*}{0.037} \\
\hline No & 24 & 72.8 & 1,133 & 84.2 & \\
\hline \multicolumn{6}{|l|}{ Atopic dermatitis } \\
\hline Yes & 14 & 42.4 & 45 & 3.3 & \multirow[t]{2}{*}{0.001} \\
\hline No & 19 & 57.6 & 1,299 & 96.7 & \\
\hline Exclusive breastfeeding & & & & & \\
\hline$<4$ months & 12 & 36.4 & 421 & 31.3 & 0.269 \\
\hline$\geq 4$ months & 21 & 63.6 & 923 & 68.7 & \\
\hline Total duration of breas & feed & & & & \\
\hline$\leq 6$ months & 3 & 9.1 & 144 & 10.7 & 0.261 \\
\hline$>6$ months & 30 & 90.9 & 1,154 & 85.9 & \\
\hline No breastfeeding & 0 & 0 & 46 & 3.4 & \\
\hline
\end{tabular}

${ }^{a}$ Based on our findings in post hoc tests, statistically significant differences were identified between subgroups. In particular, FA ratios were $2>1,2>3$ and $5>3$. 
Table 5. Risk factors for FA development based on results of multivariate logistic regression analysis

\begin{tabular}{lcc}
\hline Risk factors & Odds ratio $(95 \% \mathrm{CI})$ & p value \\
\hline Sex (male) & $1.37(0.46-4.05)$ & 0.568 \\
Birth season & 1 & \\
$\quad$ Spring & $1.94(0.29-12.94)$ & 0.493 \\
$\quad$ Summer & $0.76(0.09-5.95)$ & 0.796 \\
$\quad$ Autumn & $1.61(0.28-9.32)$ & 0.592 \\
$\quad$ Winter & 1 & \\
Socioeconomic level & $0.50(0.10-2.37)$ & 0.385 \\
$\quad$ Low & $1.34(0.11-15.34)$ & 0.813 \\
$\quad$ Medium & $0.97(0.02-48.02)$ & 0.990 \\
$\quad$ High & $3.56(0.14-88.78)$ & 0.439 \\
Maternal vitamin E intake during pregnancy & $3.83(0.54-26.76)$ & 0.176 \\
Maternal folic acid intake during pregnancy & $1.54(0.06-38.50)$ & 0.790 \\
Maternal allergic disease & $18.90(1.59-224.05)$ & 0.020 \\
Paternal allergic disease & $5.77(0.40-81.82)$ & 0.195 \\
Allergic disease in a sibling & $1.01(0.99-1.03)$ & 0.149 \\
Exclusive breastfeeding time $(\geq 4$ months) & & \\
Cord blood IgE level & & \\
\hline
\end{tabular}

Adana, which is comparable to the $1.45 \%$ found in our birth cohort study conducted at the same center 20 years later.

For the diagnosis of FA, a detailed analysis of the patient's history should be followed by an evaluation based on laboratory tests, and the diagnosis should be confirmed with a food challenge test, since self-reported food hypersensitivity tends to be overestimated [23]. In only $30 \%$ of all cases, the FA diagnosis is confirmed with a FA test $[2,18]$. In our study, only $18.2 \%$ of the infants with positive SPT and/or sIgE test, but without a history of FA, had a positive OFC. Consequently, parents are sometimes not aware of symptoms related to FA. This condition should be taken into consideration and parents should be informed about the findings of FA in developing countries. However, this statistics reached $50 \%$ in the presence of at least one positive laboratory test result along with an allergic history. In addition, as our findings reveal, an OFC test in infants with positive SPT and/or SIgE and a history of allergy might yield positive OFC results that exceed expectations. The main limitation of our study is the small size of infant subgroups included in the diagnostic procedure, which increased the difficulty in identifying factors predicting an FA diagnosis.

Symptoms of FA observed in several studies share some common characteristics. Skin reactions are most commonly observed among FA cases, and many studies worldwide support this observation $[18,19]$. Consistent with the literature, skin reactions were the major finding (74\%) during OFC in our infants.
In birth cohort studies, cow's milk and eggs were the most common allergens responsible for FA in children younger than 12 months [21]. Similarly, foods that were most commonly associated with FA in the current study were cow's milk (51.3\%) followed by eggs (43.6\%). Products containing cow's milk (e.g. baby formula or yogurt) are major contributors because they continue to be initiated as the first primary supplemental foods in our country and region, and it may be suggested that the increased prevalence of cow's milk allergy may be associated with current dietary habits.

Many meta-analyses have shown that relying on breastfeeding as the sole source of nutrition may contribute to the development of oral tolerance and could prevent some FAs and atopic disorders [7]. The protective effect of breastfeeding may be due to several factors: decreased exposure to allergenic food, the secretory IgA content of breast milk provides passive protection against foreign proteins and pathogens, and soluble factors in breast milk which may induce earlier maturation of the gut barrier and the infant's immune response [24]. Moreover, different cohort studies have provided various results regarding the relationship between the risk of FA and breastfeeding. Some studies have reported an increased risk with breastfeeding whereas others reported a decreased one, and some studies even found no relationship [25]. In the present study, we could not find any relationship between breastfeeding and FA development. This result suggests that hereditary and/or environmental risk factors are more important for FA. 
In recent studies, in agreement with our results, male gender [26], infantile eczema [27] and a family history of atopy $[28,29]$ have been determined as important risk factors for the development of FA. Moreover, many studies have shown an association with $\mathrm{AD}$. The relationship between $\mathrm{AD}$ and FA is well known. Infants with $\mathrm{AD}$ are reported to be sensitized mainly to food allergens [30-33]. However, others have shown that infants sensitized to food allergens may also have an increased risk for the development of wheezing and $\mathrm{AD}$ [34]. In this study, the frequency of wheezing and $\mathrm{AD}$ was found to be significantly higher among infants with than without FA.

Several studies have evaluated the association between FA and family history. The risk for allergy is reported to be increased among cases with a family history of allergy $[28,29]$. Schnabel et al. [21] found that early-sensitized children with a history of parental atopy were associated with persistent FA. Interestingly, according to the results of our study, a history of allergy in a sibling was a risk factor for the development of FA.

Use of cord blood IgE as a predictor of allergic diseases in infancy has already been investigated [35]. Among these studies, a birth cohort study by Pesonen et al. [36] found a significantly higher incidence of FA and $\mathrm{AD}$ in subjects with elevated cord blood IgE levels, and the presence of higher IgE levels in the cord blood was a major risk factor for FA. In our study, we did not observe a sta- tistically significant association between the development of FA and cord blood IgE levels.

Recently, a possible association between FA and foodspecific IgA levels has been studied. Konstantinou et al. [37] aimed to clarify the relationship between food sIgA levels and their role in tolerance induction. They demonstrated an effect of food sIgA on tolerance induction, but did not find any correlation between peripheral blood IgA levels and tolerance. In our study, cord blood IgA levels were not associated with FA outcome.

In conclusion, in this long-term, prospective study, FA prevalence rates and risk factors were similar to those reported in the literature. Further studies are needed to elucidate the relationship between cord blood IgE levels and allergic diseases. Nowadays, there is no proven method of preventing the development of FA. We believe that our results provide further insight into FA development and trigger future studies aiming to improve the management of FA by health care services and to develop programs dedicated to the prevention of allergic diseases.

\section{Acknowledgment}

We thank the staff of the Pediatric Allergy and Immunology Laboratory for performing SPT and blood collection, and Gülșah Seydaoğlu for her valuable support in statistical analyses. This study was supported by a research grant (TF2010LTP17) from Çukurova University.

\section{References}

1 Lack G: Epidemiologic risks for food allergy. J Allergy Clin Immunol 2008;121:1331-1336.

2 Venter C, Pereira B, Grundy J, Clayton CB, Roberts G, Higgins B, Dean T: Incidence of parentally reported and clinically diagnosed food hypersensitivity in the first year of life. J Allergy Clin Immunol 2006;117:1118-1124.

3 Altıntaş D, Guneşer S, Evliyaoğlu N, Yüksel B, Atici A, Serbest M: A prospective study of cow's milk allergy in Turkish infants. Acta Paediatr 1995;84:1320-1321.

4 Keil T, Wickman M, Kull I, Alm J: Unique collaboration of European birth cohort studies on asthma and allergy in the GA2LEN network. 2007, http://www.eaaci.net/.

5 Zeiger RS, Heller S: The development and prediction of atopy in high-risk children: follow-up at age seven years in a prospective randomized study of combined maternal and infant food allergen avoidance. J Allergy Clin Immunol 1995;95:1179-1190.
6 McBride D, Keil T, Grabenhenrich L, Dubakiene R, Drasutiene G, Fiocchi A, Dahdah L, Sprikkelman AB, Schoemaker AA, Roberts G, Grimshaw K, Kowalski ML, Stanczyk-Przyluska A, Sigurdardottir S, Clausen M, Papadopoulos NG, Mitsias D, Rosenfeld L, Reche M, Pascual C, Reich A, Hourihane J, Wahn U, Mills EN, Mackie A, Beyer K: The EuroPrevall birth cohort study on food allergy: baseline characteristics of 12,000 newborns and their families from nine European countries. Pediatr Allergy Immunol 2012;23: 230-239.

7 Grimshaw KE, Maskell J, Oliver EM, Morris RC, Foote KD, Mills EN, Roberts G, Margetts $\mathrm{BM}$ : Introduction of complementary foods and the relationship to food allergy. Pediatrics 2013;132:1529-1538.
8 Milner JD, Stein DM, McCarter R, Moon RY: Early infant multivitamin supplementation is associated with increased risk for food allergy and asthma. Pediatrics 2004;114:27-32.

9 Kaan A, Dimich-Ward H, Manfreda J, Becker A, Watson W, Ferguson A, Chan H, ChanYeung M: Cord blood IgE: its determinants and prediction of development of asthma and other allergic disorders at 12 months. Ann Allergy Asthma Immunol 2000;84:37-42.

10 Halonen M, Stern D, Taussig LM, Wright A, Ray CG, Martinez FD: The predictive relationship between serum IgE levels at birth and subsequent incidences of lower respiratory illness and eczema in infants. Am Rev Respir Dis $1992 ; 146: 866-870$.

11 Magnusson CJM: Maternal smoking influences cord serum IgE and IgD levels and increases the risk for subsequent infant allergy. J Allergy Clin Immunol 1986;78:898-904. 
12 Bousquet J, Heinzerling L, Bachert C, Papadopoulos NG, Bousquet PJ, Burney PG, Canonica GW, Carlsen KH, Cox L, Haahtela T, Lodrup Carlsen KC, Price D, Samolinski B, Simons FE, Wickman M, Annesi-Maesano I, Baena-Cagnani CE, Bergmann KC, BindslevJensen C, Casale TB, Chiriac A, Cruz AA, Dubakiene R, Durham SR, Fokkens WJ, Gerth-van-Wijk R, Kalayci O, Kowalski ML, Mari A, Mullol J, Nazamova-Baranova L, O'Hehir RE, Ohta K, Panzner P, Passalacqua G, Ring J, Rogala B, Romano A, Ryan D, Schmid-Grendelmeier P, Todo-Bom A, Valenta R, Woehrl S, Yusuf OM, Zuberbier T, Demoly P; Global Allergy and Asthma European Network; Allergic Rhinitis and Its Impact on Asthma: Practical guide to skin prick tests in allergy to aeroallergens. Allergy 2012; 67:18-24.

13 Keil T, McBride D, Grimshaw K, Niggemann B, Xepapadaki P, Zannikos K, Sigurdardottir ST, Clausen M, Reche M, Pascual C, Stanczyk AP, Kowalski ML, Dubakiene R, Drasutiene G, Roberts G, Schoemaker AF, Sprikkelman AB, Fiocchi A, Martelli A, Dufour S, Hourihane J, Kulig M, Wjst M, Yazdanbakhsh M, Szépfalusi Z, van Ree R, Willich SN, Wahn U, Mills EN, Beyer K: The multinational birth cohort of EuroPrevall: background, aims and methods. Allergy 2010;65:482-490.

14 Bindslev-Jensen C, Ballmer-Weber BK, Bengtsson U, Blanco C, Ebner C, Hourihane J, Knulst AC, Moneret-Vautrin DA, Nekam K, Niggemann B, Osterballe M, Ortolani C, Ring J, Schnopp C, Werfel T; European Academy of Allergology and Clinical Immunology: Standardization of food challenges in patients with immediate reactions to foods - position paper from the European Academy of Allergology and Clinical Immunology. Allergy 2004;59:690-697.

15 Dogruel D, Bingöl G, Altıntaş DU, Yılmaz M, Kendirli SG: Prevalence of and risk factors for atopic dermatitis: a birth cohort study of infants in southeast Turkey. Allergol Immunopathol 2015;15:122-126.

16 Platts-Mills TA: The allergy epidemics: 1870 2010. J Allergy Clin Immunol 2015;136:3-13.

17 Depner M, Ege MJ, Genuneit J, Pekkanen J, Roponen M, Hirvonen MR, Dalphin JC, Kaulek V, Krauss-Etschmann S, Riedler J, Braun-Fahrländer C, Roduit C, Lauener R,
Pfefferle PI, Weber J, von Mutius E; PASTURE Study Group: Atopic sensitization in the first year of life. J Allergy Clin Immunol 2013;131:781-788.

18 Eller E, Kjaer HF, Host A, Andersen KE, Bindslev-Jensen C: Food allergy and food sensitization in early childhood; results from the DARC cohort. Allergy 2009;64:1023-1029.

19 Chen J, Hu Y, Allen KJ, Ho MH, Li H: The prevalence of food allergy in infants in Chongqing, China. Pediatr Allergy Immunol 2011;22:356-360.

20 Keski-Nisula L, Karvonen A, Pfefferle PI, Renz H, Büchele G, Pekkanen J: Birth-related factors and doctor-diagnosed wheezing and allergic sensitization in early childhood. Allergy 2010;65:1116-1125.

21 Schnabel E, Sausenthaler S, Schaaf B, Schäfer T, Lehmann I, Behrendt H, Herbarth O, Borte $\mathrm{M}$, Krämer U, von Berg A, Wichmann HE, Heinrich J; LISA Study Group: Prospective association between food sensitization and food allergy: results of the LISA birth cohort study. Clin Exp Allergy 2010;40:450-457.

22 Kuo HC, Liu CA, Ou CY, Hsu TY, Wang CL, Huang HC, Chuang H, Liang HM, Yang KD: Partial protein-hydrolyzed infant formula decreased food sensitization but not allergic diseases in a prospective birth cohort study. Int Arch Allergy Immunol 2011;154:310-317.

23 Rona RJ, Keil T, Summers C, Gislason D, Zuidmeer L, Sodergren E, Sigurdardottir ST, Lindner T, Goldhahn K, Dahlstrom J, McBride D, Madsen C: The prevalence of food allergy: a meta-analysis. J Allergy Clin Immunol 2007;120:638-646.

24 Hogendorf A, Stańczyk-Przyłuska A, Sieniwicz-Luzeńczyk K, Wiszniewska M, Arendarczyk J, Banasik M, Fendler W, Kowalski $\mathrm{M}$, Zeman K: Is there any association between secretory IgA and lactoferrin concentration in mature human milk and food allergy in breastfed children. Med Wieku Rozwoj 2013; 17:47-52.

25 Jarvinen KM, Makinen-Kiljunen S, Suomalainen H: Cow's milk challenge through human milk evokes immune responses in infants with cow's milk allergy. J Pediatr 1999; 135:506-512.

26 Kelly C, Gangur V: Sex disparity in food allergy: evidence from the PubMed Database. J Allergy 2009;2009:159845.
27 Tariq SM, Stevens M, Matthews S, Ridout S, Twiselton R, Hide DW: Cohort study of peanut and tree nut sensitisation by age of 4 years. BMJ 1996;313:514-517.

28 Tsai HJ, Kumar R, Pongracic J, Liu X, Story R, Yu Y, Caruso D, Costello J, Schroeder A, Fang Y, Demirtas H, Meyer KE, O'Gorman MR, Wang X: Familial aggregation of food allergy and sensitization to food allergens: a familybased study. Clin Exp Allergy 2009;39:101109

29 Kim J, Chang E, Han Y, Ahn K, Lee SI: The incidence and risk factors of immediate type food allergy during the first year of life in Korean infants: a birth cohort study. Pediatr Allergy Immunol 2011;22:715-719.

30 Lio PA: Atopic dermatitis and food allergies: true, true and related? Arch Dis Child Educ Pract Ed 2007;92:56-60.

31 Kusel MM, Holt PG, de Klerk N, Sly PD: Support for 2 variants of eczema. J Allergy Clin Immunol 2005;116:1067-1072.

32 Park JH, Choi YL, Namkung JH, Kim WS, Lee JH, Park HJ, Lee ES, Yang JM: Characteristics of extrinsic versus intrinsic atopic dermatitis in infancy: correlations with laboratory variables. Br J Dermatol 2006;155:778-783.

33 Ricci G, Patrizi A, Baldi E, Menna G, Tabanelli M, Masi M: Long-term follow-up of atopic dermatitis: retrospective analysis of related risk factors and association with concomitant allergic diseases. J Am Acad Dermatol 2006; 55:765-771.

34 Novembre E, de Martino M, Vierucci A: Foods and respiratory allergy. J Allergy Clin Immunol 1988;81:1059-1065.

35 Merrett T, Burr M: Is the determination of cord blood total IgE levels any value in the prediction of atopic disease? Clin Exp Allergy 1992;22:506.

36 Pesonen M, Kallio MJT, Siimes MA, Elg P, Björgsten F, Ranki A: Cord serum immunoglobulin $\mathrm{E}$ as a risk factor for allergic symptoms and sensitization in children and young adults. Pediatr Allergy Immunol 2009;20:1218.

37 Konstantinou GN, Nowak-Wegrzyn A, Bencharitiwong R, Bardina L, Sicherer SH, Sampson HA: Egg-white-specific IgA and IgA2 antibodies in egg-allergic children: is there a role in tolerance induction? Pediatr Allergy Immunol 2014;25:64-70. 